\title{
Filistorias
}

(PPGHIS/UnB) №. 30, Brasília, Jan - Jul 2017 ISSN 2316-1191

Recebido: 22/01/2017

Aprovado: 03/02/2017

\section{Porto e liberdade: o surgimento das associações operárias em Itajaí (SC) no começo do século XX.}

André Luiz Rosa*

\section{Resumo:}

O presente artigo visa ofertar ao leitor a possibilidade de o mesmo conhecer o início das práticas operárias associativas na cidade de Itajaí (SC), no começo do século XX. O texto traz à luz o papel dos trabalhadores de Itajaí, incluindo descendentes de escravos e exescravos, no que tange sua organização política e social no período pós-abolição da escravatura. O modo como isso ocorreu, os atores sociais que integraram esse cenário, os personagens antagônicos, o contexto social etc., são exposto no texto, pois são condicionantes que integram o caminho que levou à formação da classe operária de Itajaí. Palavras-Chave: Associação Operária; Atividade Portuária; Descendentes de Escravos.

\begin{abstract}
:
The purpose of this article is to offer the reader the possibility of knowing the beginning of workers associations in the city of Itajaí (SC), in the beginning of the 20th century. The text brings to surface the role of the workers from Itajaí, including descendants of slaves and former slaves, in their political and social organization in the post-abolition period of slavery. As it happened, the social actors who integrated this scenario, the antagonistic characters, the social context, i.e., are exposed in the text, because there are conditions that make up the path that led to the formation of the working class from Itajaí.
\end{abstract}

Keywords: Workers Association; Port Activity; Descendants of Slaves.

\footnotetext{
* Graduado em História pela Universidade do Estado de Santa Catarina - UDESC, em 2003; e mestre, também em História, pela Universidade Federal de Santa Catarina - UFSC, em 2011. Professor da Rede Estadual de Educação de Santa Catarina e dos municípios de São José e Florianópolis, no período de 2005 a 2008.
} 
Engana-se quem pensa que a organização do trabalhador está intimamente ligada à área predominantemente urbana, com forte organização fabril. No Brasil, muitas organizações operárias nasceram em ambientes que não eram caracterizados como sendo “industrializados". No cenário nacional, as organizações de trabalhadores começaram a surgir a partir da segunda metade do século XIX, impulsionadas pelo papel do imigrante, ${ }^{1}$ pelas práticas abolicionistas, pela formação de grupos de libertos etc. ${ }^{2}$ Inicialmente essas formas associativas, muito comum na virada do século XIX para o século XX,eram materializadas na formação de entidades beneficentes, que prestavam auxílio pecuniários aos seus associados, quando os mesmos ficavam impossibilitados de trabalhar. Quando ocorria um falecimento, a família do associado também era amparada. As associações beneficentes não tinham como atuação central a luta e as reivindicações em prol de reajuste salarial e demais condições de trabalho do associado. Essas exigências se integrariam posteriormente, sobretudo no século $\mathrm{XX}$, ao conjunto de manifestações dos sindicatos.

Itajaí, cidade cujo processo migratório de maior ênfase se deu com os açorianos, percebeu, desde a segunda metade do século XIX, na atividade portuária a maior concentração de trabalhadores. Cidade cujas redes sociais eram muito ligadas à condição financeira, existia em sua sociedade um círculo restrito de famílias que desfrutavam também do sucesso do porto.

Tanto o comércio quanto as poucas indústrias locais eram vinculados às famílias "ilustres" de Itajaí. Os jornais e os poucos clubes sociais eram também pertencentes aos mesmos ramos familiares. O tecido social de Itajaí era ajustado de tal forma que qualquer remontagem seria algo impensado. Os grupos que atuavam na atmosfera política atuavam conjuntamente na atividade profissional, nos espaços de sociabilidade, na imprensa etc.

O Clube Atiradores, que foi fundado em abril de 1895, possuía membros das famílias Bauer, Müller ${ }^{3}$ e Heil. O Grêmio Literário Três de Maio, por sua

\footnotetext{
${ }^{1}$ Uma das funções primordiais das Beneficentes era a de prestar auxílio nos momentos de enfermidades, como na entidade criada pelos colonositalianos (muitos eramtrabalhadores da roça) em São Caetano do Sul (SP), que "surgiu em 1879 e teve como uma de suas finalidades o sepultamento de mortos (...)" (MARTINS, 2002: 181).

${ }^{2}$ Há o interessante caso da Beneficente Socorro Mútuo dos Homens de Cor, fundada em 1873, na cidade do Rio de Janeiro, cujo viés assistencial também fora marcante. Dentre os atributos dessa Entidade, destaca-se o auxílio "aos membros em caso dedoença ou idade avançadaou às famílias em caso de falecimento; ajuda financeira para custear o funeral e auxílio para a soltura em caso de prisão." (MENDES, 2015: 10).

3 Pedro Bauer era comerciante. A família Bauer possuía também firma de exportação e importação. GuilhermeMüller foi construtor do Hospital Santa Beatriz e um dos fundadores da Escola Alemã. Atuou na política, sendo que, em 26 de julho de 1890, por ato do Governo Estadual, Guilherme Müller foi nomeado o
}

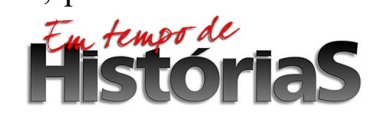


vez, teve como primeiro presidente, no ano de 1900 (ano de sua fundação), o Superintendente Municipal Pedro Ferreira e Silva, além de contar na diretoria com Arno Konder e Tibúrcio de Freitas. Esse, no ano de 1904, lançara o jornal Novidades, juntamente com Adolfo Konder. Já a Sociedade Estrella d'Oriente, fundada no ano de 1897, contava, em Novembro de 1899, com Samuel Heusi ${ }^{4}$ (presidente), João Guedes da Fonseca (Diretor), Arno Konder (Tesoureiro), Alcebíades Seara ( $1^{\circ}$ Secretário) e entre outros. (ROSA, 2011: 34).

O porto era a porta da cidade (e assim continua), pois foi por meio dele que teve início o processo de crescimento da cidade. A dinâmica econômica da cidade fora estimulada pela atividade portuária, que favorecia a frequente movimentação de mercadorias. O fluxo circulatório de mercadorias fez a cidade de Itajaí perceber o aumento considerável no número de casas comerciais e pequenas indústrias. A relevância do porto e sua necessidade de melhorias foram percebidas pelo governo federal, que expediu, no ano de 1905, normas para organização e aperfeiçoamento do porto. Os trabalhos iniciaram em 1907, e promoveram o melhoramento da barra de acesso, uma vez que, em virtude da pouca profundidade do rio Itajaí-Açu, muitos navios não conseguiam chegar ao cais.

Por outro lado, os habitantes de Itajaí também se regozijavam com o movimento no porto. As entradas de embarcações faziam nascer prolongadas conversas. As pausas dos paquetes, geralmente breves, ofertavam aos viajantes a possibilidade de visitar o comércio local para conhecê-lo, para comprar uma revista, um presente, uma roupa, um alimento etc.

(...) Pois eram nessas fugazes esperas que as senhoras itajaienses aproveitam o momento para espiar os trajes das ilustres madames, as quais se valiam da ocasião de interrupção da viagem para caminhar pelo comércio local. Muitas dessas janotas senhoras eram provenientes de cidades maiores, como Rio de Janeiro, Florianópolis e Santos. Assim sendo, suas vestimentas espelhavam o que de mais moderno e chique havia no momento. Tonalidades dos vestidos, modelos de chapéus e qualidade do tecido; enfim, tudo era observado pelas moças e senhoras de Itajaí, pois não tardaria muito para que uma ou outra viesse a adornar-se com semelhantes trajes. (Ibidem: 33).

primeiro Intendente Municipal republicano de Itajaí, empossado em 04 de agosto perante o Conselho Municipal. Já Gabriel Heil era proprietário do Hotel do Commercio (atual Grande Hotel de Itajaí).

${ }^{4}$ Samuel Heusi fez parte da vida política de Itajaí, começando no império e adentrando ao período republicano. A saber: membro da câmara municipal, de 1883- 1886 e de 1887-1890. Já na República, foi vereadordurante a Revolução Federalista, em novembro de 1892, e permaneceu até março de 1894. Neste ano a "ordem" foi restabelecida e ocorreram as eleições do Conselho Legalista. Nessas eleições, Samuel continuou edil. No fim de 94, foi nomeado superintendente municipal, permanecendo no cargo até abril do ano seguinte, quando se realizou a segunda eleição municipal Legalista. Voltou a ser eleito vereador nos seguintes mandatos de 1899 a 1903 e de 1903 a 1907. Ocupou o cargo de superintendente em 1907, para o mandato até 1911 e, depois, de 1911-1915, para vereador novamente. De 1919 a 1923, seu filho, Marcos Gustavo Heusi, também integrou a câmara de Vereadores.

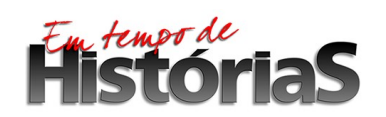


O porto era o local de parada, era o espaço destinado às conversas, ao trabalho, aos festejos pelo regresso de alguém ou às lágrimas pela partida de um familiar etc. Nas proximidades do porto se encontravam as casas comerciais mais conhecidas, as quais recebiam, com frequência, os passageiros dos paquetes que paravam por alguns instantes no porto de Itajaí.

Tendo em vista toda importância econômica do porto e todo envolvimento social com as atividades desempenhadas naquele espaço, foi ali também que iniciaram as primeiras manifestações operárias de Itajaí. Por se tratar de um espaço aberto e de livre circulação, a atmosfera portuária reunia comerciantes de posse, descendentes de escravos, ex-escravos, trabalhadores vindos de outras cidades etc. Foi nesse cenário social que Itajaí começou a perceber as manifestações de grupos de trabalhadores. Muitos desses trabalhadores haviam sentido o peso da escravidão, e estavam no descortinar do século XX, organizando-se politicamente, envolvendo-se socialmente e integrando-se profissionalmente.

\section{O início da organização de classe}

A primeira manifestação dos trabalhadores de Itajaí, no sentido de uma organização coletiva, ocorreu em 1902, com a fundação da Sociedade Operária Beneficente Itajahyense SOBI, cujos membros eram majoritariamente integrantes de atividades portuárias. Alguns componentes dessa associação eram descendentes de escravos, mas a ausência de documentos sobre a vida da organização não nos permite avançar e buscar indícios que apontem se havia um viés somente classista ou também o era étnico. Há poucos dados sobre essa Associação, bem como é reduzido o número de documentos ainda existentes. Sabe-se que o mandato da diretoria era de dois anos, e o primeiro corpo diretivo estava formado com os seguintes membros: João da Cruz e Silva - presidente, Romão Julião, João Jacob Heusi Sobrinho - $1^{\circ}$ secretário, João Anselmo Teixeira, Moyses Zeferino Lopes, José dos Santos Castro e Francisco Olegário dos Santos.

O primeiro presidente, João da Cruz, fez nascer o primeiro jornal na cidade, no ano de 1884, intitulado O Itajahy, cuja tiragem não atingiu mais do que seis edições. Nascido numa família com parcos recursos obteve somente contato inicial com o ambiente escolar, porém, 
seu conhecimento e aproximação com os estudos se deram em virtude da arte da leitura, a qual o fez poeta. ${ }^{5}$

Vale destacar a atuação de um dos membros dessa diretoria, que é o senhor João Jacob Heusi Sobrinho, que, no mesmo período em que integrou a diretoria da SOBI, desempenhou também a atividade de delegado municipal. Trata-se de uma relação que, num primeiro momento, apresenta-se como surpreendente, pois se analisarmos o papel que cabe à associação operária e o papel de um delegado perceberam que há um distanciamento de propósitos.

\section{Municipalidade de Itajahy \\ EDITAL}

João Jacob Heusi Sobrinho faz público saber que até ás onze horas da manhã de 31 do corrente mez, a superintendência municipal receberá proposta para o fornecimento dos materiaes e para a mão de obra com referência á construcção de cães em frente á igreja matriz. No passo municipal serão dadas minuciosas informações aos interessados. ${ }^{6}$

Paço Municipal, $1^{\circ}$ de Outubro de 1903.

O Delegado Municipal João Jacob Heusi Sobrinho. (O ARAUTO, 1903:03).

Notas nos periódicos locais recebiam a rubrica de João Jacob H. Sobrinho; ora como integrante da entidade operária; ora como membro de órgão governamental.

\section{S.O.B. Itajahyense}

De novo convido aos srs. Associados para a sessão de assembléia geral extraordinária, que não se tendo realizado no dia 19 do corrente, por falta de número legal. Foi adiada para 3 de julho p. entrante. Se ainda desta vez não comparecer número legal ficará, de conformidade com o disposto no art. ${ }^{\circ}$ 58dos estatutos, constituída a assembléia geral com o número de sócios presentes (...) Itajahy, 21 de junho de 1904.O $1^{\circ}$ Secretário João Jacob Heusi Sobrinho. $^{7}$ (NOVIDADES, 1904: 2)

As passagens jornalísticas acima confirmam a atuação do delegado, tanto na esfera da beneficente quanto na esfera policial. Essa relação entre delegado e SOBI não deve ser percebida como sendo um ato de sujeição dos integrantes da Beneficente, nem mesmo compreendida como uma atividade repressiva por parte do agente policial. Pelo contrário, poderia representar, na visão dos membros da SOBI, algo salutar, visto que, estreitar o

\footnotetext{
${ }^{5}$ João da Cruz e Silva, popularmente conhecido por mestre Janja, faleceu em 31 de dezembro de 1909, o que causou profunda consternação no meio operariado local. Atribui-se ao falecimento de mestre Janja um dos motivos que contribuíram com o declínio da Itajahyense, pois a entidade não conseguiu arregimentar outra pessoa que exercesse liderança entre os trabalhadores.

${ }^{6}$ As notas jornalísticas e demais documentos de época preservam, no presente artigo, a gramática do período relatado.

${ }^{7}$ João Jacob Heusi Sobrinho ocupou o cargo de $1^{\circ}$ Secretário da SOBI na gestão 1903 -1904. Nos quadros diretivos que se seguiram seu nome não consta.
}

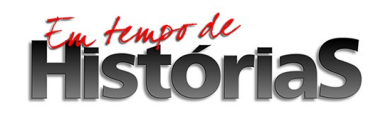


relacionamento com autoridades, como já explicitado anteriormente, poderia aumentar as condições da própria beneficente em atender melhor seus membros.

Contudo, a participação do delegado não impediu a SOBI de realizar suas atividades, como também não garantiu nenhum privilégio a ela. Cabe reforçar, por oportuno, que a SOBI era uma entidade beneficente e, como tal, não tinha como foco de suas ações o enfrentamento com os patrões. Tendo como vertente o aspecto filantrópico das beneficentes, a participação de autoridades se configurava em prática comum, pois a notoriedade dessas pessoas na atmosfera local ampliava a rede de solidariedade, favorecendo, dessa forma, um maior contingente de associados que, não raro, precisava ser amparado frequentemente.

$\mathrm{O}$ auxílio aos associados e familiares em casos de moléstias e falecimento era o ponto central da existência da SOBI e de suas congêneres pelo Brasil. Badaró destaca o papel da Imperial Associação Tipográfica Fluminense, cujos associados

(...) contribuíam com uma mensalidade para ter direito a recorrer ao caixa da mutualidade em função de determinadas necessidades, como ajuda monetária em casos de doenças e para enterros - as formas de auxílio mais comuns nos estatutos -, bem como em situações de invalidez, prisão ou pensão para viúvas. (MATTOS, 2008:91-92).

Essa aproximação entre associações beneficentes e personalidades não se restringia somente ao espaço social de Itajaí. Pelo contrário, tal relação se configurou numa prática comum durante boa da Primeira República, pois, dentre os interesses, de ambos os lados, com essa aproximação, havia a tentativa das entidades beneficentes em adquirir reconhecimento da sociedade local, visto que, nas primeiras três décadas do século XX, as greves e movimentos operários eram resolvidos na esfera policial. "Foi assim na greve de operários numa fábrica de sapatos no Rio de Janeiro, em 1902; no movimento grevista na Cia. Doca de Santos, em 1904; na greve de ferroviários paulistas, em 1906 (...) (PATTOS, 1999). Não diferente ocorriam nas manifestações também dos trabalhadores nos portos pelo Brasil, como na greve de 1906, ocorrida no Rio de Janeiro. Naquela oportunidade, (...) a diretoria do Centro do Comércio de Café encontrou-se com os representantes de nove firmas comissionarias, ensacadoras e exportadoras e nomeou uma comissão para ir à Chefatura Central de Polícia pedir providências (...).” (CRUZ, 2000: 247).

Assim sendo, estreitar laços com políticos, delegados e demais pessoas de notório reconhecimento social poderia ser uma excelente estratégia por parte das entidades de amparo

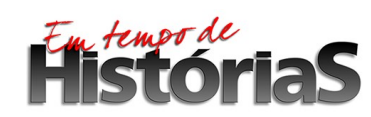


ao trabalhador, visto que o contato com personalidades poderia representar certa "segurança", quando de situações que envolvessem os trabalhadores e que, não raro, poderiam culminar na porta da delegacia.

Havia uma prática no Brasil de as autoridades locais receberem convites para apadrinhar as associações operárias. Essa foi uma estratégia utilizada durante boa parte do século XX e que trazia para perto dos trabalhadores pessoas de reconhecida influência na cidade. Essa prática pavimentava um estreitamento de laços entre operários com a sociedade, além de ofertar à associação muito respeito desde o seu nascimento. Essa iniciativa não ocorreu somente em Itajaí. Pelo contrário, muitas cidades do Brasil $^{8}$ assistiram situação semelhante. Em Florianópolis, por exemplo,

(...) Pode-se compreender a permanência de Heitor Blum no quadro associativo do Grêmio Instrutivo e Beneficente dos Empregados no Comércio e na Congregação de Marítimos e Pescadores, pois ele também era agente de companhias de navegação. O caso de Blum ilustra também outro conjunto de interesses que levavam esses sujeitos sociais a filiarem-se em entidades de trabalhadores - os eleitorais. Blum teve uma carreira política bastante estável, herdada de seu pai Cel. Emilio Blum. Heitor Blum assumiu cargos importantes, como o de promotor público, em 1910, da comarca de São Miguel (hoje município de Biguaçu), e da Palhoça, de onde saiu somente em 1913, por ter sido nomeado procurador-geral da república, em caráter interino, função que ocupou três vezes (1913, 1921 e 1924). Em 1914, foi oficial do gabinete de Felipe Schmidt e também nomeado diretor da Escola de Aprendizes Artífices da cidade. Foi Secretário do Interior e Justiça, no governo de Adolfo Konder e, em 1927, foi nomeado prefeito de Florianópolis, exercendo o mandato até 1930. (LEUCHTENBERGER, 2009: 130).

Analisar a fundação da Sociedade Itajahyense é entender além das manifestações operárias. Conjectura-se que a referida Sociedade tenha sido composta, dentre outros membros, por ex-escravos. E, diante daquele cenário de "liberdade" e de "autonomia", faziase prudente compor laços sociais pautados numa relação amistosa, de entendimento e de cooperação, evitando, assim, enfrentamentos e divergências com os personagens do poder estabelecido. Quiçá, algumas tensões tenham ocorrido no período de cativeiro, ${ }^{9}$ e, mesmo

\footnotetext{
${ }^{8}$ Há o caso da cidade de Pelotas - RS, na relação com as Sociedades de Socorro Mútuo. Ver em: SILVA JR, Adhemar Lourenço. As Sociedades de socorros mútuos: estratégias privadas e públicas $-1854-1940$. Tese de Doutoramento PUC - RS. Porto Alegre, 2004.

${ }^{9}$ Várias situações de brigas entre escravos e seus senhores, e entre escravos e membros da população ocorreram em Itajaí ao longo da segunda metade do século XIX, cujas condenações, em sua imensa maioria, tinham o escravo como alvo. Os relatos, as testemunhas e as "motivações", invariavelmente eram contra o escravo. Para
}

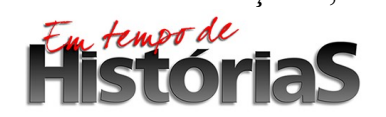


com a liberdade, possivelmente, no entender daqueles personagens que integraram a SOBI, as relações entre membros das diversas camadas sociais ainda dependiam de aprimoramento.

Badaró chama atenção para as situações conflituosas e de tensões envolvendo exescravos com a sociedade, sobretudo os trabalhadores na pós-abolição, tendo em vista que havia uma disputa pelas "mesmas ocupações e pelos mesmos clientes." (BADARÓ, 2008: 49). O autor destaca ainda, que em virtude das poucas opções disponíveis no mercado de trabalho, a atividade nas ruas se configuravam como questão de sobrevivência. A busca por trabalho, as disputas locais e a necessidade de abdicar definitivamente das amarras da escravidão, levaram ao surgimento de formas de sociabilidade e de amparo por parte dos libertos. Badaró destaca várias iniciativas nesse sentido realizadas por ex-cativos na cidade do Rio de Janeiro, cidade onde houve considerável concentração de trabalhadores livres após 1888. As opções de trabalho para os libertos eram diminutas, tendo em vista a pouca qualificação dos mesmos, a qual os levou a outra forma de "escravidão".

A ideia anterior reforça a existência de ex-escravos na atuação da Itajahyense, pois o trabalho no porto se configurou em arregimentar pessoas com boa compleição física, visto que as atividades relativas ao cais eram essencialmente dependentes da força braçal. ${ }^{10} \mathrm{Se}$ isso ocorreu, não se configurou num movimento peculiar a Itajaí. Evidente que não. Outras regiões do Brasil perceberam o mesmo fluxo de ex-escravos. No Rio de Janeiro, enquanto ainda vigorava a escravidão, era comum encontrar escravos de ganho desempenhando algum ofício nas atividades portuárias. A prática perdurou pós 1888, sendo que as muitas associações operárias na orla portuária contaram com a participação de descendentes de escravos e até de ex-escravos. Essa permanência do trabalho portuário, pré e pós 1888 , no porto do Rio de Janeiro, criam Segundo CRUZ, “(...) uma forte linha de continuidade entre os escravos e libertos dos velhos tempos imperiais e os proletários da Primeira República (...)” (op.cit.274).

A SOBI não se configurou numa associação de determinado grupo profissional. Em seus quadros eram admitidos trabalhadores dos mais diversos ofícios. Em assembleia realizada em 21 julho de 1904, “foram admitidos sócios contribuintes os cidadãos Edmundo da Souza Cunha, músico compositor, Jovino Euzébio da Silva, carpinteiro naval, e Eurico da Silva Fontes, curtidor."(NOVIDADES, 1904: 2).

mais detalhes sobre conflitos envolvendo escravos, libertos e escravos de ganhos, ver em: SILVA, José Bento Rosa; COSTA, Moacir. Negros em Itajaí: da invisibilidade a visibilidade - mais de 150 anos de história. Itajaí: Casa Aberta Editora, 2010.

${ }^{10}$ Essa situação sofreu alteração nas últimas décadas, face a introdução de máquinas e demais tecnologias que auxiliam o embarque, o desembarque e o armazenamento da carga.

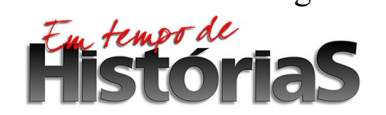


O estatuto da Sociedade Itajahyense determinava que a mesma tivesse "por fim auxiliar pecuniariamente os seus associados no caso de enfermidade, invalidez e amparar as famílias pelo fallecimento dos chefes, fornecendo ou concorrendo com o funeral.” (Estatuto da SOBI, 1908: 1). ${ }^{11}$

Possivelmente esse caráter abrangente da Itajahyense tenha se dado por algumas peculiaridades do período, tais como: a união de trabalhadores em torno de uma associação forte e pioneira, visto que, pela documentação existente, a SOBI inaugurou na cidade esse viés associativo. Além desse aspecto, talvez a não restrição de ingresso para pessoas que exerciam atividades variadas tenha se dado em face da possibilidade de insucesso da entidade caso optasse pela via da unicidade classista. Se fosse levado a cabo a ideia de restringir a atividade profissional que pudesse integrar a Itajahyense, seguramente a mesma teria enormes dificuldades em se manter, visto a diminuta população que havia em Itajaí naquele período. Em toda cidade, contando com a vila e os arrabaldes, "no ano de 1900 a população era de 9.745 habitantes; em 1905, 11.462; e em 1910, 13.48."12

Os festejos promovidos pela Itajahyense também traziam consigo essa pluralidade, pois buscavam integrar os trabalhadores nos mesmos espaços que os identificassem como membros de um único grupo, cujos eventos se configurariam em momentos de celebração da identidade coletiva, cujos laços eram fortalecidos no cotidiano de suas atividades, no simbolismo do auxílio mútuo - que era a essência da SOBI -, na consolidação do papel do trabalhador livre, cujo preterido recente, para alguns membros da Itajahyense, foi o de cativeiro, se não para si, mas para algum membro de suas famílias.

Dentre os eventos promovidos pela Beneficente Itajayhense, há a comemoração do $1^{\circ}$ de Maio.

\section{CONVITE AOS OPERÁRIOS}

Festa do Trabalho $-1^{\circ}$ de MAIO

Para comemorar esta grandiosa data, consagrada a festa do trabalho, à Sociedade Operária Beneficente Itajahyense, convida sem distinccão de classe, a todos operários desta cidade, a comparecerem no $1^{\circ}$ de Maio, às 9 horas da manhã, no edifício social, a fim de incorporados, percorrerem as principaes ruas acompanhados da banda musical, seguindo logo após até a fábrica de cerveja do Sr. Alois Kormann, onde realizar-se-a um sumptuoso

\footnotetext{
${ }^{11} \mathrm{O}$ resumo do Estatuto da Sociedade Operária Beneficente Itajahyense, de 30 de março de 1908, está disponível no Acervo Cartório Heusi, na cidade de Itajaí.

${ }^{12}$ Informações relativas ao senso de Itajaí no século XIX e início do século XX podem ser encontradas na seção Fundos da Paróquia do Santíssimo Sacramento de Itajaí, no Arquivo Público Municipal.
}

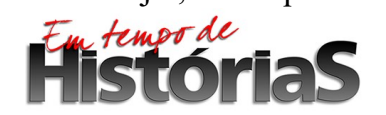


convescote, passando ali esse dia voltando-se à tarde, novamente incorporados (...) (O PHAROL, 1909: 3).

A celebração do $1^{\circ}$ de Maio, que marcou o início do século em Itajaí, não representava apenas a integração com os associados para festejar uma data importante. Tanto a SOBI como também as demais entidades operárias reforçavam seus vínculos associativos e suas práticas nessa data. A nota acima destaca a criação de uma prática que evidenciou a SOBI. Integrar os trabalhadores - associados ou não da Beneficente -, desfilar pela cidade e promover a sociabilidade constituíram uma linguagem simbólica de um segmento social que se fazia presente no universo social local, sendo também protagonista de sua história.

A segunda associação operária surgiu em Itajaí no ano de 1903, um ano após o nascimento da Beneficente Itajahyense. A novel entidade foi batizada com o nome de Sociedade 13 de Maio, e trazia em seu cerne descendentes de escravos. Não foi possível estabelecer uma relação entre a 13 de Maio e a Itajahyense, a ponto de afirmar que a nova Entidade teria sido constituída por integrantes da SOBI, ou que teria ocorrido uma divergência no interior desta Entidade e, assim, os dissidentes teriam fundado aquela Associação. O que sabemos é que a 13 de Maio era constituída essencialmente por negros.

Não há certeza se a nova Entidade possuía uma vertente operária, mas seguramente ela foi étnica. Como bem destacou um memorialista de Itajaí, "a 13 de Maio congregava os homens de cor (...)."13 (LINHARES, 1997: 60).

O nome da Associação nos impulsiona a refletir sobre sua composição, e isso pode corroborar com a hipótese de ser uma entidade voltada apenas aos negros de Itajaí. O nome da Entidade foi escolhido como forma de marcar definitivamente o fim do cativeiro e as "possibilidades" que deveriam surgir a partir daquela data.

Os eventos da 13 de Maio convergiam no sentido de integrar a população negra local, como nos festejos em regozijo ao terceiro aniversário da Sociedade. Conforme matéria que ganhou espaço no periódico,

A Sociedade 13 de Maio comemorou o $3^{\circ}$ aniversário de sua instalação com os festejos projetados decorando com palmeiras, flores e arcos o salão;

\footnotetext{
${ }^{13}$ Linhares nasceu em 1896, e foi proprietário dos jornais $O$ Commércio e o $O$ Pharol. Este adquirido em 1924 e fechado em 1936, durante o governo de Getúlio Vargas, por defender ideias Integralistas. A sua obra é uma compilação dos artigos e crônicas (que propunha contar um pouco de sua vida na cidade através de sua lembrança) que escreveu para o jornal O Popular, entre os anos de 1958 a 1960. Faleceu em 1968. A obra de Linhares é em sua plenitude a lembrança de quem viveu no período relatado.
}

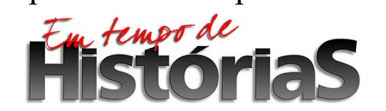


colocando no centro a bandeira nacional e pavilhão do Estado o retrato de D.Pedro $2^{\circ}$. À direita José do Patrocínio o invicto propagandista. Na véspera correu animadíssimo baile durou até madrugada; às 5 horas da tarde de 13 presidiu a secção o Sr. Manoel Miranda, a pedido do atual presidente Sr. Álvaro Machado dos Passos fazendo alocução referente à data, dando a palavra a diversos oradores; encerrada a secção sairão todos em marche "auxsflambeaux" percorrendo diversas ruas com entusiastos vivas ao som da banda musical Estrela e foguetes a Uffa! É digna de louvor a maneira correta com que desempenharam essa função. (O Pharol apud SILVA, 2011: 100).

A magnificência do festejo na sede da 13 de Maio sugeri que havia uma boa organização no interior da Entidade e conhecimento acerca dos personagens que, de alguma forma, integraram o repertório social que culminou com o fim da escravidão. A inserção dos retratos de D. Pedro II e José do Patrocínio representou um ato de deferência por parte dos membros da 13 de Maio. O tributo prestado a José do Patrocínio pode ser percebido por dois vieses: o primeiro, por ter sido ele um jornalista reconhecido por sua defesa pelo abolicionismo; já o segundo, por ter sido no ano anterior ao ato de instalação do retrato o ano do falecimento do grande defensor do fim da escravidão. ${ }^{14}$ Além de todo envolvimento de José do Patrocínio com a causa antiescravista, o fato de ele ser negro seguramente criou esse laço sentimental a distância, por assim dizer, com os negros da 13 de Maio.

Cabe destacar, por oportuno, que os festejos descritos anteriormente, tanto o promovido pelo SOBI ( $1^{\circ}$ de Maio) bem como o da 13 de Maio,traziam consigo um caráter não somente lúdico, mas, sobretudo, faziam nascer uma prática que marcou o operariado local. Ambos os eventos se caracterizaram pelo simbolismo criado e pelas práticas culturais peculiares do conjunto de trabalhadores. A inauguração dos retratos, o desfile pela cidade, a exposição do estandarte e os vínculos arregimentados com a comunidade negra - no caso da 13 de Maio -, esboçavam um conjunto de manifestações associativas, reforçado ao longo dos anos e que caracterizou o operariado de Itajaí. Esse conjunto de expressão do operariado é o que Batalha chama de cultura associativa, que é entendida como sendo o "conjunto de propostas e práticas culturais das organizações operárias, a visão de mundo expressa nos discursos, bem como os rituais que regem a vida das associações que muitas vezes são herdados de formas de organização mais antigas (...)" (BATALHA, 2004: 99).

\footnotetext{
${ }^{14}$ A trajetória política de José do Patrocínio não foi tão grandiosa quanto sua defesa em prol do abolicionismo. Patrocínio soube usar muito bem a impressa para divulgar suas ideias, e mostrar à sociedade que não haveria progresso social e desenvolvimento econômico num país escravista.
}

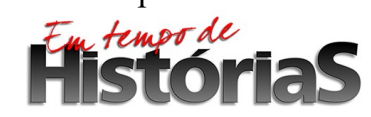


Ao longo do ano de 1906, os comunicados nas páginas dos periódicos sobre a 13 de Maio foram diminuindo, tendo findado definitivamente a partir de 1907. A tese corrente é de que a 13 de Maio tenha se unido à Sociedade Beneficente 15 de Novembro, que surgiu no final de 1906. Quiçá tal união tenha ocorrido pelo fato de a 15 além de agregar muito negros o que, num primeiro momento, manteria o ideal da 13 de Maio -ser uma entidade de amparo ao operariado do porto. Sim, exclusivamente das atividades portuárias. A 15 de Novembro foi a primeira organização operária a se dedicar a uma atividade em particular. Em seu estatuto, a entidade expunha seus intentos:

\section{Estatuto da S.B 15 de Novembro Capítulo 1 \\ Da sociedade e seus fins.}

Art. $2^{\circ}$ A Sociedade tem por fim:

Parágrafo $1^{\circ}$ - Agremiar todas as pessôas que se occupam ou venham a occupar-se, nesta cidade, nos trabalhos de praça, portos, cargas e descarga de navios, mantendo entre ellas a maior harmonia possível.

$\S 2^{\circ}$ - Regular os horários dos trabalhos, estabelecer os respectivos salários. (O Pharol, 1908: 2).

Os propósitos relativos à questão salarial estabelecidos pela 15 de Novembro eram novos na cidade de Itajaí, ao menos do ponto de vista estatutário; pois tais finalidades não integravam as diretrizes da Sociedade Operária Beneficente Itajahyense. Enquanto a Itajahyense propunha traçar mais os aspectos humanitários e altruístas, empenhando auxílio aos trabalhadores enfermos, a 15 de Novembro, por sua vez, além de prestar auxílio pecuniário, passou a atuar também nos assuntos concernentes à atividade laboral e as condições do trabalhador, como a questão salarial, por exemplo. Além disso, o que diferenciou a 15 de Novembro foi essa dedicação aos profissionais do porto, visto que eram operários cujas condições de vida se assemelhavam e cujas dificuldades os uniam em virtude da ausência do poder público no tocante às necessidades elementares da população. Além desses aspectos, integrava a formação da 15 de Novembro um forte viés étnico, visto que essa entidade trouxe consigo muitos negros, alguns descendentes de escravos, inclusive. "Dentre eles, destacamos: Silvério Joaquim Ramos, "tio Silvério" (ex-escravo) e Sebastião Lucas Pereira (filho de escravo), dentre outros." (SILVA, 2001: 63).

Provavelmente muitos desses descendentes de escravos e até de ex-escravos que integraram a 15 de Novembro formaram as fileiras da SOBI ou da 13 de Maio. Infelizmente,

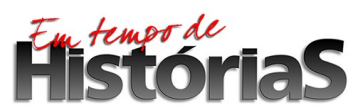


os parcos documentos que restaram não nos permitem assegurar essa hipótese. Contudo, é possível conjecturar, mediante os fatos ocorridos, que a 15 de Novembro tenha sido a extensão da 13 de Maio. Alguns aspectos contribuem para essa dedução. Dentre eles, destaco os seguintes: a 15 de Novembro fora fundada em 15 de novembro de 1906, sendo que as últimas notas nos periódicos sobre a 13 de Maio não passaram do mês de agosto desse mesmo ano,o que sugeri poder ter havido uma articulação entre os membros da 13 e os da futura Sociedade, a fim de promover a união de ambas as Associações. Além disso, um dos fundadores da 15 de Novembro foi fundador da 13 de Maio. Refiro-me a João Marques Brandão.

Além desses aspectos, a 15 de Novembro possuía em sua gênese uma forte e marcante presença de negros, situação semelhante ao que ocorreu com a 13 de Maio. É aceitável que os negros que integraram esta Associação tenham migrado àquela. Contudo, em que pese os argumentos expostos aqui, fica o questionamento: mas por qual motivo os membros de uma associação teriam escolhido outro rumo em suas práticas associativas? Um dos caminhos que nos levam a acreditar nessa "migração" é o fato de a 13 de Maio não ser uma entidade com propósitos trabalhistas, com vistas à defesa de classe. Situação adversa da 15 de Novembro, que, com número considerável de negros na atividade portuária, percebeu que poderia reunir aspectos étnicos e trabalhistas numa mesma causa, numa mesma associação, num mesmo propósito. O depoimento de Maria Leocádia, filha de Pedro Antonio Fayal, um dos fundadores da 15 de Novembro, reforça a tese defendida acima. Segundo Maria,

Ele [seu pai] falava que se precisava de uma Sociedade, porque o trabalho no porto era tudo assim à vontade. Os patrões tiravam gente, botavam gente, quando queriam. Eles escolhiam os trabalhadores para trabalhar. Então meu pai achou que aquilo estava errado. Então ele chamou os amigos Bernardino Neves, Sebastião Lucas Pereira, Artur Raulino, o preto Constantino e disse: vou fundar uma Sociedade. E eles concordaram. (Dossiê: Biografias e informações genealógicas. Arquivo Histórico de Itajaí).

Voltando a tratar da Sociedade Operária Beneficente Itajahyense, ela perdurou por mais alguns anos, mas o que a diferiu da 15 de Novembro foi o seu público. A 15, desde sua fundação passou a reunir somente os trabalhadores do porto, independente da atividade que era executada. Ela reunia tanto os estivadores quando os trabalhadores que manipulavam a carga fora do navio, chamados de terrestres. A Entidade só "perderia” sua soberania no porto no ano de 1922, quando alguns marítimos fundariam a Sociedade União Beneficente dos

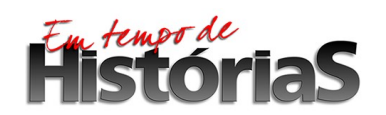


Estivadores de Itajaí (SUBEI). Após o surgimento da SUBEI, os estivadores passaram a integrar esta Associação; enquanto a 15 de Novembro permaneceu apenas com os trabalhadores da terrestre. ${ }^{15}$

Ainda sobre a Itajahyense, ela findou suas atividades em 1917, embora não faltaram tentativas para reerguê-la. Enquanto essa Entidade permaneceu ativa ela sempre buscou integrar trabalhadores das mais variadas atividades. Algumas opiniões acreditam que tenha sido esse o motivo de sua ruína, visto que por não conseguir unidade em torno de uma causa específica e por abranger várias "frentes", acabou não integrando todos numa mesma força, pois as propostas e as atenções eram diversificadas. Se, em seu começo, a não restrição de acesso foi salutar à Itajahyense, no entanto, com o passar do tempo e o crescimento da atividade portuária, voltar atenção ao público trabalhador do porto seria estratégico, visto ser o ambiente profissional que reunia o maior número de operários. Escolha essa feita pela 15 de Novembro desde sua fundação.

É perfeitamente admissível que a 15 de Novembro se fortaleceu ao longo do tempo, embora tenham ocorridos tensões e divergências em seu cerne. Porém, as divergências também ajudaram a entidade a se refazer. No decorrer dos anos, a 15 precisou alterar sua nomenclatura em dados momentos, sobretudo com a Lei de Sindicalização de Vargas, de 1931. Com o advento dessa regulamentação, a entidade passou a se chamar Sindicato dos Trabalhadores em Trapiches e Armazéns, em atividade até os dias de hoje. A importância dessa Associação não se restringiu somente aos aspectos trabalhistas; chegou até as práticas esportivas e sociais. Foi no interior da 15 de Novembro que, no começo da década de 1920, surgiram duas importantíssimas agremiações esportivas na cidade de Itajaí: o Clube Náutico Cruz e Souza e o Humaytá Foot-Ball Club.

Tendo em vista o impedimento ao acesso de negros e operários aos clubes sociais e esportivos locais, essas categorias se organizaram com o propósito de criar seus próprios espaços de sociabilidade. Assim, surgiram, na sede da 15, em 1920, o Cruz e Souza, e, em 1921, o Humaytá Foot-Ball Club. A formação de ambas as agremiações reforça a ideia, aqui defendida, de que a 15 de Novembro convergia em seu cerne tanto causas trabalhistas como étnicas.

\footnotetext{
${ }^{15}$ São muitos os ofícios desempenhados no espaço portuário, sendo eles o do estivador, do terrestre, do conferente etc. O estivador é o trabalhador que executa atividades dentro do navio. Já os que manipulam a carga fora do navio, são chamados de Terrestres. Essa divisão ocorreu em Itajaí, com o surgimento da SUBEI.
}

\section{Filstortias}




\section{CLUB DE REGATAS CRUZ E SOUZA}

$\mathrm{Na}$ sociedade $<<15$ de Novembro $>>$, desta cidade, foi fundado domingo ultimo, por diversos homens de cor, mais um club de Regatas, que tem como patrono o inexquecível poeta catharinense Cruz e Souza, o sonhador do Bello e do Ideal. A directoria do clubrecem-fundado, é composta de diversas senhoritas, que foram aclamadas pela assembléa. Estiveram presentes á sessão de fundação do $<<$ Club Cruz e Souza $>>$, os Srs. Cel Marcos Konder, operoso Superintendente Municipal, José Eugênio Muller, Mascarenhas Passos e Oswaldo Reis pelo club $<<$ Marcílio Dias $>>$, TuffiSchead, Ralf Thieme e Raul Seára pelo club $<<$ Almirante Barroso $>>$, Albano P. Costa pela "União", Ary Macarenhas, João Neves, Pedro Santos e muitos outros cavalheiros, cujos nomes nos escaparam, aos quaes foi servida lauta mesa de doces e bebidas. Ao novel Club $<<$ Cruz e Souza $>>$, A $<<$ Uniao $>>$ deseja prosperidade. (A UNIÃO, 1920: 2).

A equipe de remo foi fundada por Francelino Rafael, Firmino Rosa, Boleslau Procópio, Antonio Pedro, Pedro Caetano Vieira, Maximiano Pereira, Manuel Euzébio Nascimento e algumas mulheres, as quais compuseram a primeira diretoria da equipe náutica. O primeiro quadro de diretores do Cruz e Souza foi o seguinte:

Presidente, Etelvina Vieira; Vice, Mariazinha Mascarenhas; $1^{\circ}$ Secretária, Maria Ramos; $2^{\circ}$, Ernestina Prateat; $1^{\mathrm{o}}$ Tesoureira, Lucília Procópio; $2^{\mathrm{o}}$, Maria Caetano; Orador, Firmino Rosa; Diretor Galpão, Francelino Rafael; 136 Instrutor, Rodolfo Reiser; Zelador de Galpão, Pedro Caetano. (REVISTA RUBRO ANIL, 1962: 69).

Dentre os membros fundadores do Cruz e Souza, destacamos Francelino Rafael, que também foi da 15 de Novembro e que, em 1922, já integrava o quadro associativo da Sociedade União Beneficente dos Estivadores de Itajaí (SUBEI). ${ }^{16}$ Já Firmino Rosa, foi marítimo do Loyde Brasileiro e "Viajou à Europa e aos Estados Unidos. "No exterior, travou conhecimento com a doutrina marxista-leninista, recém vitoriosa na União Soviética (...)" (Cf. Dossiê:Negros de Itajaí. Arquivo Municipal de Itajaí). Firmino Rosa sempre integrou as lutas da comunidade negra em Itajaí. Nessa cidade, ajudou a fundar o Cruz e Souza, a SUBEI (em 1922) e a Aliança Beneficente dos Trabalhadores em Trapiches e Armazéns, no ano de 1929. ${ }^{17}$ Contribuiu também com a fundação do Sindicato dos Estivadores de São Francisco do

\footnotetext{
${ }^{16}$ Mais detalhes são encontrados na Ata da Reunião de 10 de junho de 1922. In: Livro de atas do Sindicato dos Estivadores de Itajaí.

${ }^{17}$ Pordivergências com a diretoria da 15 de Novembro, Firmino Rosa e outros integrante da entidade romperam com a 15, formando, em 1929, Aliança Beneficente dos Trabalhadores em Trapiches e Armazéns, que passou a atuar no mesmo espaço e "disputar", junto com a 15, os mesmos trabalhadores. Contudo, com a Lei de Sindicalização, a qual exigia a unicidade sindical por categoria, a recém Associação deixou de existir. Mais detalhes, ver em ROSA, op. cit.
}

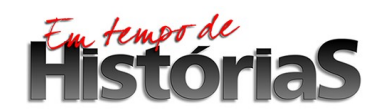


Sul e dos Marítimos do Rio de Janeiro (no qual fez parte da diretoria). Bolesláu Procópio, por sua vez, também integrou, no ano de 1922, a SUBEI.

À medida que a cidade, o porto e as exigências sociais cresciam, aumentava também os desafios das organizações operárias de Itajaí. Os condicionantes sociais, as lutas que se emergiram ao longo dos anos e as disputas por melhores condições de trabalho passaram a se intensificar na vida operária da cidade, como no acordo firmado em 1918, que assim como outros, reforçaram o valioso papel das associações operárias ao longo de suas trajetórias.

\section{S. B. 15 DE NOVEMBRO}

Para conhecimento dos Srs. socios publica-se abaixo o officio n 465 do Sr. Superintendente Municipal, datado de 28 de Novembro: Srs. Membros as directoria as sociedade de trabalhadores 15 de Novembro - nesta cidade: De accordo com as combinações feitas por mim com os commerciantes exportadores desta praça ficou resolvido que, do dia 26 do corrente em diante, vencerão os trabalhadores do porto a diária de $4 \$ 000$ pôr dia de $91 / 2$ horas e de noite $7 \$ 500$. As horas de serviço serão pagas de dia, das 6 ás 6 , a razão $\$ 500$ à hora e de noite, também das 6 ás 6 a razão de $\$ 800$ a hora. Estou certo de que acceitareis este accordo, o qual virá de certo modo attenuar os males que affligem a classe operária.

Saúde e Fraternidade (assig) Marcos Konder - Superintendente. (O Pharol, 1917:3).

Os anos da década de 1920 trariam novos ares políticos, nova movimentação social, nova atmosfera operária, etc. Tudo isso gerado por grandiosos eventos, como a Primeira Guerra Mundial, a Revolução Russa, a repercussão da Greve Geral de 1917, em São Paulo, o Movimento Tenentista, a Semana de Arte Moderna etc. Enfim, o descortinar dos anos ofertaria ao movimento operário e às entidades locais novos desafios. Contudo, seu processo de consolidação revelou que as bases já estavam fortes, e todos os dilemas serviriam para arregimentar cada vez mais as instituições operárias da cidade.

Essas experiências nascidas no alvorecer operariado de Itajaí contribuíram sobremaneira para pavimentar o caminho percorrido pelos trabalhadores locais, sobretudo a partir do começo do século XX. Os eventos festivos, os apelos ao patronato, as manifestações associativas, as iniciativas altruístas em prol do operário etc., integraram o repertório de ações que propiciaram o seu contínuo fazer-se. Tomando classe operária como formação histórica, compreendendo que há recuos e avanços, perdas e ganhos, estratégias e insucessos, o movimento está num permanente processo evolutivo, visto que “(...) as classes nunca estão prontas no sentido de acabadas" (HOBSBAWM, 1987: 273).

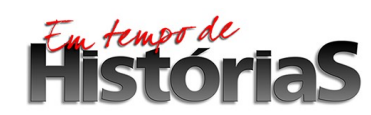




\section{Referências Bibliográficas}

\section{Fontes Primárias}

Revista Rubro Azul. Publicação do Clube Náutico Marcílio Dias, Itajaí, 1962.

Jornais: O Pharol, O Arauto, Novidades e A União.

\section{Acervos do Arquivo Público de Itajaí}

Fundos da Paróquia do Santíssimo Sacramento de Itajaí.

Dossiê: Biografias e informações genealógicas.

Dossiê: Negros de Itajaí.

\section{Acervo Cartorial}

Estatuto da Sociedade Operária Beneficente Itajahyense. 1908.

\section{Fontes Secundárias}

BATALHA, Claudio H.M. Cultura associativa no Rio de Janeiro da Primeira República. In: BATALHA, Claudio H.M; SILVA, Fernando Teixeira e FORTES, Alexandre. Culturas de Classe: identidade e diversidade na formação do operariado. Campinas: Editora da Unicamp, 2004.

CRUZ, Maria Cecília Velasco. Tradições negras na formação de um sindicato: Sociedade de Resistência dos Trabalhadores em Trapiche e Café, Rio de Janeiro, 1905-1930. In:Afro-Ásia. Salvador, número 24, 2000.

HOBSBAWM, Eric J. Mundos do trabalho:novos estudos sobre história operária. Rio de Janeiro: Paz e Terra, 1987.

LEUCHTENBERGER, Rafaela. O Lábaro protetor da classe operária: As Associações voluntárias de socorrosmútuos dos trabalhadores em Florianópolis - Santa Catarina (1886-1932). Dissertação de Mestrado em História. Instituto de Filosofia e Ciências Humanas/UNICAMP. Campinas/SP, 2009.

LINHARES, Juventino. O que a memória guardou. Itajaí: Editora da Univalli, 1997.

MARTINS, José de Souza. Subúrbio: vida cotidiana e história no subúrbio da cidade de São Paulo: São Caetano, do fim do império ao fim da República Velha. São Paulo: Hucitec, 2002.

MATTOS, Marcelo Badaró. Escravizados e Livres. Experiências comuns na formação da classe trabalhadora carioca. Rio de Janeiro: Bom Tempo, 2008.

MENDES, Camila Menegardo. Redes de solidariedade, associativismo e liberdade nas associações beneficentes negras do Rio de Janeiro noséculo XIX. In: Anais do XXVIII Simpósio Nacional de História. Florianópolis: ANPUH, 2015.

PATTOS, Maria Helena Souza. Estado, Ciência e política na Primeira República: a desqualificação dos pobres. Estudos Avançados. Vol. 13 n 35. São Paulo.

ROSA, André Luiz. Operários da bola: um estudo sobre a relação dos trabalhadores com o futebol na cidade de Itajaí (SC), entre as décadas de 1920 a 1950. Dissertação de Mestrado. Universidade Federal de Santa Catarina: Florianópolis, 2011.

SILVA, José Bento Rosa da. Nacionalidade e etnicidade no litoral do Atlântico Sul: Foz Do Itajaí - SC (1906). Itajaí: Casa Aberta, 2011.

Do porão ao convés: estivadores de Itajaí entre a memória e a História. Recife: UFPE, 2001. (Tese de Doutoramento, $286 \mathrm{p}$ ).

; COSTA, Moacir. Negros em Itajaí: da invisibilidade a visibilidade - mais de 150 anos de história. Itajaí: Casa Aberta Editora, 2010.

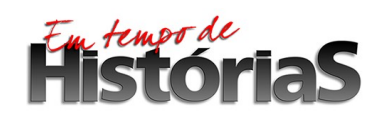


SILVA JR, Adhemar Lourenço. As Sociedades de socorros mútuos: estratégias privadas e públicas - 1854 1940. Tese de Doutoramento PUC - RS. Porto Alegre, 2004.

\section{Filstorias}

(PPGHIS/UnB) No. 30, Brasília, Jan - Jul 2017 ISSN 2316-1191 